\title{
Intoxicação espontânea por Sorghum sudanense em bovinos leiteiros no Rio Grande do Sul ${ }^{1}$
}

INDEX TERMS: Plant poisoning, sorghum Sudanense, Sudan grass, cyanogenic glycosides, cattle.

RESUMO.- Descreve-se um surto de intoxicação espontânea por Sorghum sudanense (aveia de verão, capim-sudão) em um rebanho de bovinos leiteiros no município de Triunfo, Rio Grande do Sul. Essa planta é utilizada como forrageira em diversas regiões do estado; entretanto, intoxicações ocasionais são associadas com a formação de ácido cianídrico por hidrólise dos glicosídeos cianogênicos presentes na planta. Vinte e nove vacas Holandesas foram colocadas, no final do dia, em um potreiro de $800 \mathrm{~m}^{2}$, onde uma pastagem estabelecida de capim-sudão rebrotava e atingia $30 \mathrm{~cm}$ de altura. Na manhã seguinte, quase todo pasto havia sido consumido e três vacas foram encontradas mortas. Não foram relatados sinais clínicos, mesmo porque os animais não foram observados durante a noite. Exceto pela presen-

\footnotetext{
${ }^{1}$ Recebido em 10 de outubro de 2011.

Aceito para publicação em 4 de novembro de 2011.

${ }^{2}$ Setor de Patologia Veterinária, Faculdade de Veterinária, Universidade Federal do Rio Grande do Sul (UFRGS), Av. Bento Gonçalves 9090, Porto Alegre, RS 91540-000, Brasil. *Autor para correspondência: davetpat@ufrgs.br
}

ça de folhas mastigadas de capim-sudão nas proximidades da entrada do rúmen, não foram observadas alterações macro ou microssópicas. Amostras da planta de diferentes locais no potreiro foram positivas no teste do papel picrossódico. Esses achados sugerem que as três vacas foram afetadas por intoxicação cianídrica secundária ao consumo de Sorghum sudanense.

TERMOS DE INDEXAÇÃO: Plantas tóxicas, Sorghum sudanense, aveia de verão, ácido cianídrico, glicosídeos cianogênicos, bovinos.

\section{INTRODUÇÃo}

Sorghum spp. são gramíneas anuais distribuídas em todo o Brasil que têm importância crescente na alimentação de rebanhos bovinos devido à facilidade de cultivo, crescimento rápido, produção, capacidade de perfilhamento e rebrota, além do adequado valor nutritivo (Zago 1997). A época ideal de semeadura no Sul do Brasil se estende de setembro a janeiro. A maioria das áreas plantadas é destinada para produção de silagem, contudo áreas de sorgos para pastejo 
e/ou corte verde têm emprego frequente, especialmente na bovinocultura leiteira (Ribas 2003). As espécies utilizadas como forrageiras são Sorghum sudanense (aveia de verão/ capim-sudão) e $S$. bicolor (sorgo forrageiro) (Radostits et al. 2007), além de variedades híbridas entre essas duas espécies. S. halepense (capim-de-boi) é planta invasora em margens de açudes e culturas irrigadas e que causa prejuízos importantes para a pecuária do semiárido Nordestino (Nóbrega et al. 2006). Sorghum sp. compõe um grupo de mais de 120 plantas que possuem quantidade suficiente de glicosídeo cianogênico para causar intoxicação (Radostits et al. 2007). Sorghum spp. são particularmente perigosas quando ingeridas jovens, com menos de $50 \mathrm{~cm}$ de altura. O glicosídeo cianogênico envolvido é a durrina (Kellerman et al. 2005), cuja hidrólise libera ácido cianídrico (HCN), líquido incolor e volátil, uma das substâncias mais tóxicas conhecidas (Radostits et al. 2007). Nos casos fatais, a morte resulta de anóxia generalizada em consequência da inibição da respiração celular (Riet-Correa \& Mendes 2007).

As principais plantas cianogênicas de interesse econômico incluem, no Nordeste Brasileiro, Manihot spp., especialmente M. esculenta ou maniçoba, Anadenanthera (Piptadenia) macrocarpa (angico), Piptadenia viridiflora (espinheiro ou surucucu), Cnidoscolus phyllacanthus e Sorghum halepense (Tokarnia et al. 1994, 1999, Amorim et al. 2005, Nóbrega et al. 2006, Oliveira et al. 2008). No Sul e Sudeste do país, Prunus sellowii ou pessegueiro-bravo (Saad \& Camargo 1967, Gava et al. 1992) e Cynodon dactylon ou Tifton (Gava et al. 1998) são as principais espécies envolvidas em intoxicações. No Brasil, tanto a frequência, quanto a importância das intoxicações por plantas cianogênicas são insuficientemente conhecidas. Em parte porque são raras as descrições de surtos espontâneos dessas intoxicações (Amorim et al. 2005). Este trabalho relata um surto de intoxicação espontânea por Sorghum sudanense em bovinos leiteiros no Rio Grande do Sul.

\section{MATERIAL E MÉTODOS}

Dados epidemiológicos e clínicos foram obtidos durante visita ao local, quando três vacas Holandesas aos 4, 10 e 15 anos de idade foram necropsiadas. Fragmentos de diversos órgãos foram coletados e fixados em solução de formalina tamponada a $10 \%$, processados de forma rotineira para histologia, incluídos em parafina, cortados a $3 \mu$ de espessura e corados por hematoxilina e eosina (HE). 0 teste de papel picrossódico para verificar a presença de HCN foi realizado em amostras da planta de diferentes locais do potreiro onde ocorreram as mortes. Previamente, preparou-se uma solução composta de $0,5 \mathrm{~g}$ de ácido pícrico e 5,0g de carbonato de sódio dissolvidos em $100 \mathrm{~mL}$ de água destilada (Tokarnia et al. 2000). Pequenas tiras de papel filtro foram embebidas nessa solução e fixadas, ainda úmidas, em um recipiente com amostras da planta recém-esmagada, de forma que o papel ficasse suspenso acima do material. 0 recipiente foi vedado e mantido em posição vertical, em temperatura ambiente, com registro do tempo para alteração de cor do papel.

\section{RESULTADOS}

O surto ocorreu em fevereiro de 2011, em uma propriedade rural, em Triunfo, RS, região metropolitana de Porto Alegre, onde 35 bovinos (29 vacas e seis bezerras) da raça Holandesa eram manejados para exploração leiteira. A alimentação incluía pastagem nativa, Sorghum sudanense e milheto (Pennisetum glaucum), além de concentrado à base de farelo de soja e milho. Capim-sudão era rotineiramente utilizado como forragem verde picada e servida no cocho, mas somente eram cortadas, quando as plantas atingissem 2 metros de altura. No entardecer do dia anterior à morte dos bovinos, 29 vacas foram introduzidas em um potreiro com $800 \mathrm{~m}^{2}$, onde uma pastagem de Sorghum sudanense rebrotava. As plantas haviam sido cortadas e picadas para uso no cocho há aproximadamente 15 dias e estavam com $25-30 \mathrm{~cm}$ de altura. 0 proprietário relatou que, excepcionalmente, os animais foram colocados a pastejar no local, com intuito de aproveitar a rebrota, pois a área seria utilizada para implantar outra cultura. Após a ordenha e um período de espera de 3-4 horas, nas quais os animais tiveram apenas acesso à água, mas a nenhum alimento, as vacas foram conduzidas à pastagem de capim-sudão. Na manhã seguinte, três vacas foram encontradas mortas e a pastagem mostrava aspecto de haver sido consumida (Fig.1 e 2). Na necropsia, não foram encontradas alterações macroscópicas significativas, exceto a presença de folhas mastigadas de capim-sudão nas proximidades da entrada do rúmen (Fig.3). Na microscopia, não houve al-

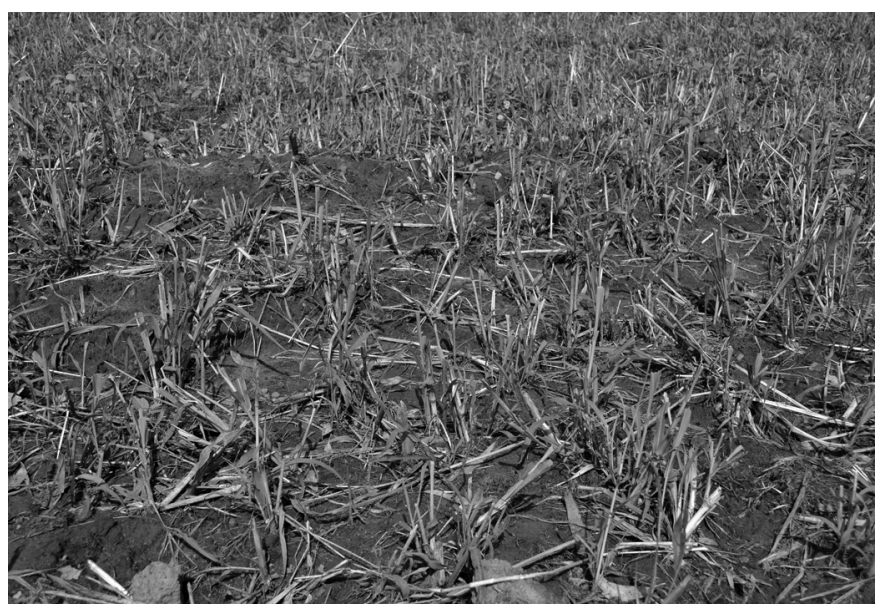

Fig.1. Aspecto da brotação de Sorghum sudanense consumida pelos bovinos intoxicados.

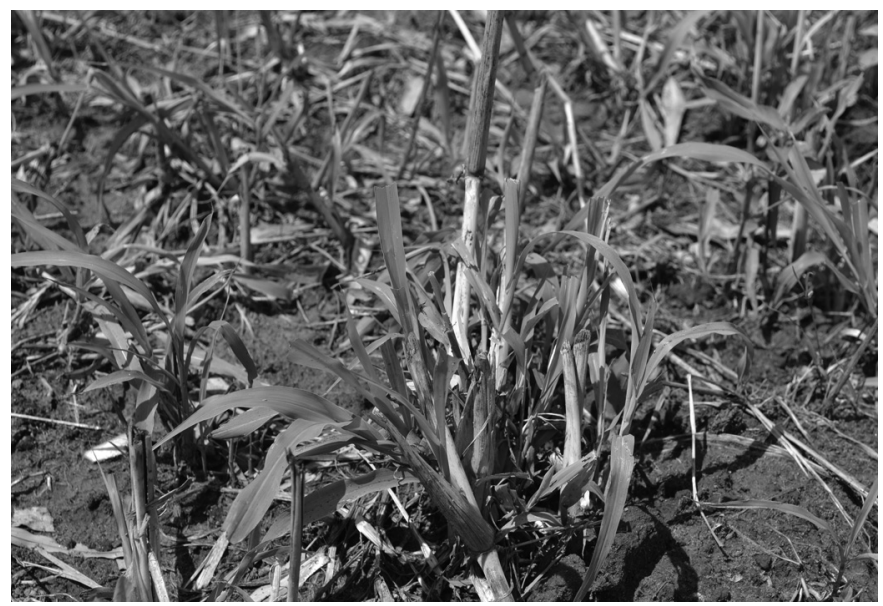

Fig.2. Detalhe da brotação de Sorghum sudanense que causou intoxicação com sinais de consumo pelos bovinos. 


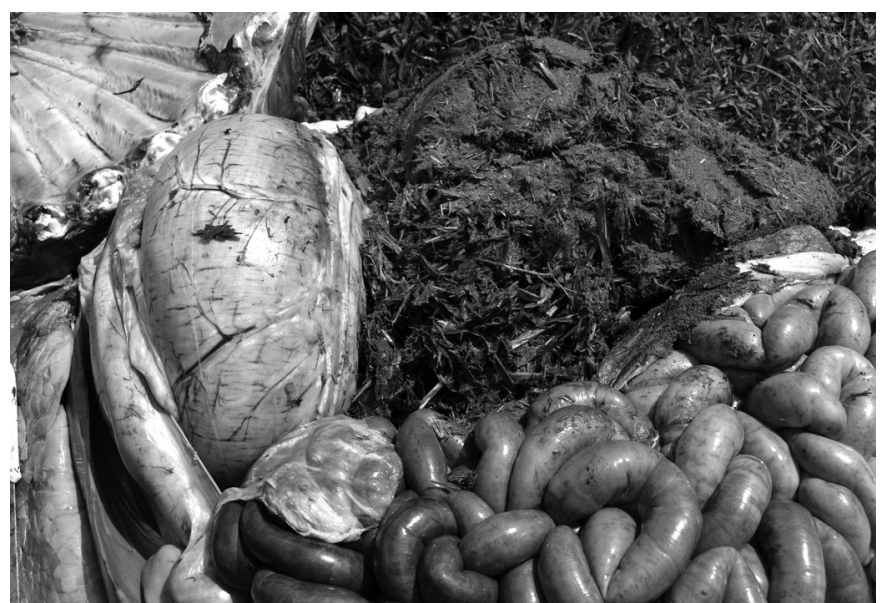

Fig.3. Folhas mastigadas de capim-sudão na entrada do rúmen de um bovino intoxicado, observado durante a necropsia.

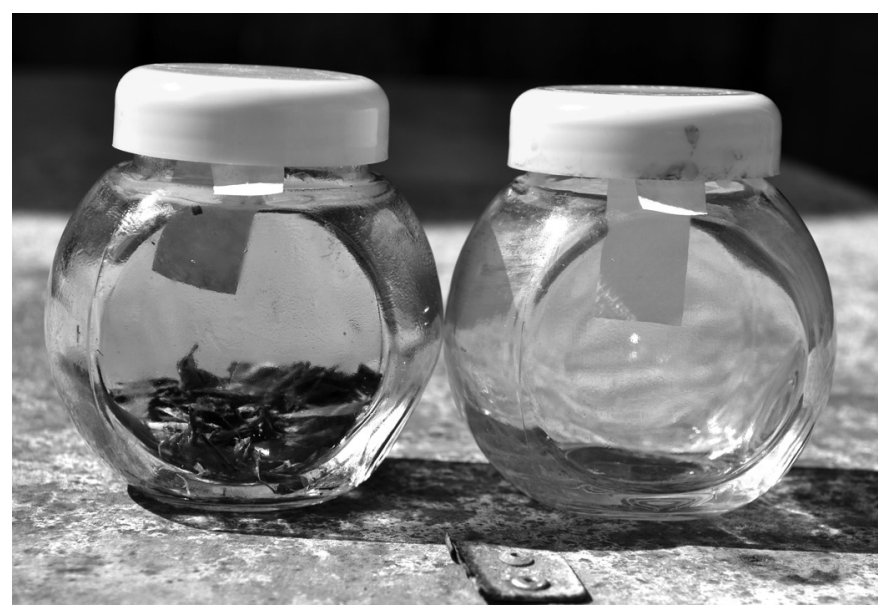

Fig.4. Teste do papel picrossódico em amostra de capim-sudão do local onde ocorreu a intoxicação. 0 aparecimento da cor vermelho-tijolo no papel do frasco à esquerda revela a presença de ácido cianídrico. No frasco à direita, o papel está na cor original amarela.

terações significativas. 0 teste do papel picrossódico em amostras da planta colhida no local onde ocorreu o surto teve uma reação acentuada (Amorim et al. 2005), pois foi positivo em tempo inferior a 3 minutos, resultado caracterizado pela mudança na coloração do papel, de amarelo para vermelho-tijolo (Fig.4).

\section{DISCUSSÃO}

As mortes súbitas, a ausência de lesões macro e microscópicas, o relato da ingestão da brotação de Sorghum sudanense, cujas amostras foram positivas no teste do papel picrossódico são evidências consideráveis para o diagnóstico de intoxicação por ácido cianídrico associada ao consumo da planta. A toxidez e a velocidade de ingestão das plantas cianogênicas constituem os fatores mais importantes para a ocorrência da intoxicação (Dowling \& McKenzie 1993, Knight \& Walter 2002, Radostits et al. 2007). Conforme também ocorreu no surto descrito aqui, os animais sofreram restrição alimentar durante o período que antecedeu o contato com a planta, o que, estimulou seu rápido consumo e, portanto, a rápida ingestão da dose tóxica (Radostits et al. 2007). A utilização da planta jovem para pastejo foi fator adicional importante nessa ocorrência de intoxicação. Sorghum spp. são tóxicas somente na fase de crescimento, quando jovens, geralmente com menos de $20 \mathrm{~cm}$ de altura, ou aproximadamente sete semanas após plantio (Riet-Correa \& Mendez 2007), período em que há maior concentração de glicosídeos cianogênicos na planta (Radostits et al. 2007).

HCN bloqueia a cadeia respiratória e impede o aproveitamento do oxigênio pelos tecidos. Bovinos intoxicados, agudamente, podem apresentar dispneia, taquicardia, tremores musculares, sialorreia, ansiedade, incoordenação motora e convulsões que precedem as mortes. Como a absorção de HCN é rápida, esses sinais ocorrem pouco tempo após, ou já durante a ingestão das plantas (Tokarnia et al. 2000, Radostits et al. 2007). Nesse caso, não foi possível a observação de sinais clínicos, pois os animais não foram observados durante o tempo de ingestão da planta e foram encontrados mortos no local. Conforme descrito em surtos de intoxicação por plantas cianogênicas (Riet-Correa \& Mendez 2007), as alterações macroscópicas e histológicas observadas nesse caso não foram significativas, exceto pela presença de folhas de capim-sudão não digeridas no rúmen, o que demonstra a velocidade de absorção e ação do HCN. 0 teste do papel picrossódico foi utilizado nesse caso para a detecção de ácido cianídrico em amostras da pastagem e foi positivo em curto período de tempo. Esse teste é rápido, qualitativo, simples e pode ser utilizado no campo em casos de suspeita de intoxicação por plantas cianogênicas (Riet-Correa \& Mendez 2007).

Além de outras plantas que contêm HCN, o diagnóstico diferencial deve incluir outras doenças e intoxicações que apresentem evolução aguda, cursem com poucos sinais clínicos e ocorram na mesma região, tais como intoxicações por Amorimia exotropica (Pavarini et al. 2011), Nerium oleander (Pedroso et al. 2009) e nitrato/nitrito (Riet-Correa \& Mendez 2007), além de carbúnculo hemático (Schild et al. 2006), fulguração (Watanabe et al. 2010) e timpanismo agudo por ingestão excessiva de leguminosas (Dalto et al. 2009). Todavia, em todos esses casos, os bovinos afetados apresentam lesões características, ou achados epidemiológicos distintos. A utilização de Sorghum spp. como forragem requer medidas preventivas para evitar a intoxicação por ácido cianídrico. Entre as mais importantes destas, inclui-se evitar a introdução de animais com fome nas pastagens de Sorghum sp., observar a fase de desenvolvimento da planta ao pastejo e considerar a utilização de variedades híbridas de Sorghum spp. com menores concentrações de glicosídeos cianogênicos.

Agradecimentos.- À Coordenação de Aperfeiçoamento de Pessoal de Nível Superior (CAPES) e ao Conselho Nacional de Desenvolvimento Científico e Tecnológico (CNPq), pelo auxílio financeiro e à médica veterinária Laura Barreto.

\section{REFERÊNCIAS}

Amorim S.L., Medeiros R.M.T. \& Riet-Correa F. 2005. Intoxicação experimental por Manihot glaziovii (Euphorbiaceae) em caprinos. Pesq. Vet. Bras. 25:179-187. 
Dowling R.M. \& McKenzie R.A. 1993. Poisonous Plants. A Field Guide. Department of Primary Industries. Editora Queensland, Australia. 164p.

Dalto A.G.C., Bandarra P.M., Pedroso P.M.O., Guagnini F.S., Leal J.S, Raymundo D.L. \& Driemeier D. 2009. Timpanismo espumoso em bovinos leiteiros em pastagem de Trifolium spp. (Leg. Caesalpinoideae). Pesq. Vet. Bras. 29:401-403.

Gava A., Stolf L., Neves D.S., Stolf O., Varaschin M.S. \& Ferreira F.M.M. 1992. Intoxicação experimental por Prunus sellowii (Rosaceae) em bovinos. Pesq. Vet. Bras. 12:1-4.

Gava A., Pilati C., Cristani J., Simões J. \& Simões L. 1998. Intoxicação cianogênica em bovinos alimentados com Tifton (Cynodon sp.). VIII CAMEV, Lages, SC. 5p.

Kellerman T.S., Coetzer J.A.W. \& Naudé T.W. 2005. Plant Poisonings and Mycotoxicoses of Livestock in Southern Africa. $2^{\text {nd }}$ ed. Oxford University Press, Cape Town, p.265-269.

Knight A.P. \& Walter R.G. 2002 A Guide to Plant Poisoning of Animals in North America. Teton New Media, Jackson, Wyoming. 367p.

Nóbrega J.E., Riet-Correa F., Medeiros R.M.T. \& Dantas, A.F.M. 2006 Intoxicação por Sorghum halepense (Poaceae) em bovinos no semi-árido. Pesq. Vet. Bras. 26:201-204.

Oliveira D.M., Pimentel L.A., Araújo J.A.S., Medeiros R.M.T., Dantas A.F.M \& Riet-Correa F.,2008. Intoxicação por Cnidoscolus phyllacantus (Euphorbiaceae) em caprinos. Pesq. Vet. Bras. 28:36-42.

Pavarini S.P., Soares M.P., Bandarra P.M., Gomes D.C., Bandinelli M.B., Cruz C.E.F. \& Driemeier D. 2011. Mortes súbitas em bovinos causadas por Amorimia exotropica (Malpighiaceae) no Rio Grande do Sul. Pesq. Vet. Bras. 31:291-296.

Pedroso P.M.O., Bandarra P.M., Bezerra Junior P.S., Raymundo D.L., Borba M.R., Leal J.S \& Driemeier D. 2009. Intoxicação natural e experimental por Nerium oleander (Apocynaceae) em bovinos no Rio Grande do Sul. Pesq. Vet. Bras. 29:404-408.
Radostits O.M., Gay C.C., Hinchcliff K.W. \& Constable P.D. 2007. Cyanogenic glycoside poisoning (cyanide hydrocyanic acid), p.1852-1855. In: Ibid. (Eds), Veterinary Medicine. $10^{\text {th }}$ ed. Saunders Elsevier, Oxford, UK.

Ribas P.M. 2003. Sorgo: Introdução e importância econômica. Documento 26, Embrapa Milho e Sorgo, Sete Lagoas, MG. 16p.

Riet-Correa F. \& Mendez M.C. 2007. Intoxicação por plantas e micotoxinas, p.177-181. In: Riet-Correa F., Schild A.L., Lemos R.A.A. \& Borges J.R.J. (Eds), Doenças de Ruminantes e Eqüídeos. Vol.2. 3르 ed. Pallotti, Santa Maria. 694p.

Saad A.D. \& Camargo W.V.A. 1967. Intoxicação cianídrica em animais domésticos. Biológico, São Paulo, 33:211-220.

Schild A.L., Sallis E.S.V., Soares M.P., Ladeira S.R.L., Schramm R., Priebe A.P., Almeida M.B. \& Riet-Correa F. 2006. Anthrax in cattle in Southern Brazil, 1978-2006. Pesq. Vet. Bras. 26:243-248.

Tokarnia C.H., Peixoto P.V. \& Döbereiner, J. 1994. Intoxicação experimental por Piptadenia macrocarpa (Leg.Mimosoideae) em bovinos. Pesq. Vet. Bras. 12:57-63.

Tokarnia C.H., Peixoto P.V., Brito M.F., Duarte M.D. \& Brust L.A.C. 1999. Estudos experimentais com plantas cianogênicas em bovinos. Pesq. Vet. Bras. 19:84-90.

Tokarnia C.H., Döbereiner J. \& Peixoto P.V. 2000. Plantas cianogênicas, p.215-221. In: Ibid (Eds), Plantas Tóxicas do Brasil. Editora Helianthus, Rio de Janeiro.

Watanabe T.T.N., Ferreira H.H., Gomes D.C., Pedroso P.M.O., Oliveira L.G.S., Bandarra P.M., Antoniassi N.A.B. \& Driemeier D. 2010. Fulguração como causa de morte em bovinos no Estado do Rio Grande do Sul. Pesq. Vet. SBras. 30:243-245.

Zago C.P. 1997. Utilização do sorgo na alimentação de ruminantes, p.9-26. In: Embrapa (Ed.), Manejo Cultural do Sorgo para Forragem (Circular Técnica 17). $2^{\mathrm{a}}$ ed. Embrapa Milho e Sorgo, Sete Lagoas, MG. 